DEPARTAMENTO DE TECNICA DE SACDE PUBLICA

(Diretor: Prof. Dr. G. H. de Paula Souza)

CADEIRA DE VENEREOLOGIA E LEPROLOGIA

(Prof. Dr. J. M. Gomes)

\title{
INQUÉRITO SOROLÓGICO PARA O DIAGNÓSTICO DA SIFILIS REALIZADO NA ZONA DO MERETRICIO DE SÃO PAULO
}

\author{
J. MARTINS DE BARROS \\ Assistente
}

Desde os tempos bíblicos constitui a prostituição um problema social. Vozes não faltaram, através dos séculos, que condenassem essa aviltante condição humana, mas sempre em bases morais e sempre em vão. De mal inextirpavel, chegou mesmo a ser considerada como sendo um "mal necèssário" (!).

Independentemente de critério moral ou social, a Medicina moderna, tomando feições novas de Medicina Social ou Saúde Pública, começou a se preocupar com o assunto, com o fito de libertar a comunidade de um número de doenças estreitamente ligadas às relações sexuais: as doenças venéreas.

Tendo-se em conta que o contágio das doenças vepéreas se faz, principalmente, através do congresso sexual, a promiscuidade nas relaçóes entre os sexos deve ser considerada, por conseguinte, como o principal meio de propagaçáo de tais doenças. Ora, a prostituição é o grau mais elevado a que pode atingir a promiscuidade sexual. Não é de admirar, portanto, que seja ela o grande reservatório dos germes das doenças venéreas, e o seu maior foco de disseminação.

Sob o ponto de vista jurídico, as definições de prostituição convergem, quase sempre, para a concepção clássica de que "prostituta é a mulher que se entrega publicamente, sem eleição, e mediante pagamento".

Sob o ponto de vista sanitário, no entretanto, prostituição é sinónimo de promiscuidade sexual, e as demais condições têm apenas interesse secundário. Deve merecer a atenção da Saúde Pública, para fins de contrôle das doenças venéreas, todo indivíduo sexualmente promíscuo, independente de "como" e "porque" essa promiscuidade é exercida. $O$ interesse do sanitarista, portanto, independe de ,razões de ordem jurídica ou moral.

Para fins de contrôle sanitário costumamos dividir em três categorias as mulheres que mantêm relações sexuais com mais de um indivíduo: promíscuas, prostitutas clandestinas e prostitutas estabelecidas em casas de tolerância. Tal classificação baseia-se, principalmente, na frequência com que tais mulheres se entregam ao ato sexual.

As promiscuas não recebem, em geral, nenhuma gratificação direta pelo ato. Têm emprêgo e só mantêm relações ocasionais com o namorado, "amiguinho" ou indivíduos com quem simpatisam. Seria êste o grau menos intenso da promiscuidade sexual feminina. Em nosso Serviço de Ambulatório temos notado que um grande contingente de promíscuas provêm das empregadas domésticas. 
As prostitutos clandestinas podem, ou não, ter, concomitantemente, um ofício honesto, mas se entregam sempre por interesse monetário. Não ficam em casa à espera do homem. Saem à rua à sua procura, ou perambulam pelos bares, hotéis, "dancings", cabarés, etc. Como precisam dispender certo tempo para encontrar um interessado, além do tempo perdido com o "flirt" preparatório, não podem elas exercer a promiscuidade sexual muito intensamente.

As prostitutas estabelecidas em bordel ou casas de "rendez-vous" são, em geral, conhecidas e fichadas pela polícia, que pode ou não exercer certo contrôle sôbre elas.

Exercem essas mulheres a mais intensa atividade sexual, elevando ao máximo a frequência da promiscuidade sexual.

Enquanto uma clandestina despende grande parte do dia ou da noite para arranjar um "freguês", a prostituta estabelecida em casa por todos conhecida, pode receber até 60 indivíduos por dia, como foi verificado em casas de tolerância em Paris.

Sob o ponto de vista da disseminação de doenças venéreas, costuma-se comparar o poder infectante dêsse tipo de prostituta com a eficácia de uma metralhadora, enquanto a clandestina teria a ação de um revólver.

Não é de se estranhar, portanto, que as estatísticas responsabilizem essas prostitutas como sendo o maior foco de contágio dos doentes portadores de doenças venéreas.

Stokes menciona como sendo de 40 a $60 \%$ o contágio dos homens das forças armadas norte-americanas na prostituição organizada.

Lentino cita um trabalho realizado na Liga de Combate à Sífilis, em 1926, onde $70 \%$ dos 1975 portadores de doenças venéreas examinados, acusavam a zona de prostituição como foco de contágio.

Segundo estatísticas de todos os países onde a prostituição é ou era permitida, o número de prostitutas clandestinas é inúmeras vezes superior ao de pros. titutas estabelecidas em casas determinadas e fichadas pela polícia.

Flexner estudando a prostituição na Europa, em 1921, mostrou que na cida. de de Berlim havia 5.000 prostitutas registradas, enquanto que o número de clandestinas era calculado em 25.000.

Na cidade do México, em 1930, havia 5.971 prostitutas inscritas, e um número de clandestinas avaliado em não menos de 20.000. Em Madrí, na mesma época, não chegavam a 3.000 as inscritas, mas as clandestinas deviam ultrapassar a cifra de 20.000. Em Paris, em 1937, J. J. Frappa calculava em 202 as casas de prostituição, com 7.600 mulheres, mas o número de clandestinas avaliado para a cidade era, segundo uns, de 40.000 , e, segundo outròs, até de 100.000 .

$\mathrm{Na}$ cidade do Rio de Janeiro, Hélio Gomes chegou a calcular o número de prostitutas clandestinas em 20.000, e M. O. de Morais, em 30.000. Ainda segundo Morais, dessas 30.000 prostitutas a Polícia Civíl tinha fichadas 6.169 mulheres, em 1942. A maioria permanecia, portanto, fora do contrôle, como dançarinas de cabarés, "dancings", etc., ou dissimulando-se nos "ateliers" de modas, institutos de beleza, hotéis, pensões e "rendez-vous" dos bairros centrais da cidade. 
Não conhecemos nenhum dado sôbre as clandestinas existentes na cidade de São Paulo e nem sabemos como avaliar devidamente o seu número. Nem sequer nos abalamos a fazer qualquer estimativa, tantas são as causas de erro que existem em tais avaliações.

Em nosso trabalho nos limitamos a examinar as prostitutas da zona do baixo meretrício da Capital, localizado no bairro do Bom Retiro.

Durante os meses de junho e julho de 1947 colhemos sangue de tôdas as mulheres residentes naquela zona, e que compreende as ruas Itabóca, Aimorés, Carmo Cintra e Ribeiro de Lima.

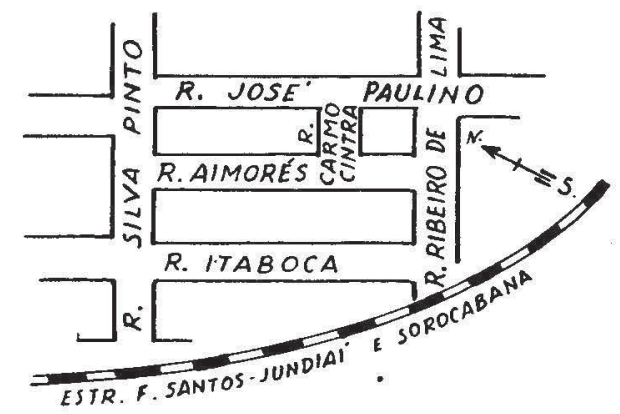

Em virtude de encontrarmos duas e mais casas transformadas em uma única pensão, e de haver algumas outras em reforma, somos levados a estimar em 140 a 150 o número total de casas da zona do meretrício de São Paulo.

Consideramos uma média de 10 mulheres habitando cada casa, incluindo as não residentes, o que dá uma população de 1.400 a 1.500 mulheres para essa zona.

Vejamos alguns dados referentes às 1.000 mulheres por nós examinadas:

\begin{tabular}{|c|c|c|c|c|c|c|c|c|c|c|c|c|c|c|c|c|}
\hline & & & & & & & & I & DE & & & & & & & \\
\hline de & 16 & anos & 2 & & de & 26 & anos & 45 & de & 36 & anos & 4 & $\mathrm{de}$ & 46 & anos & $\mathbf{3}$ \\
\hline$"$ & 17 & $"$ & 0 & & $"$ & 27 & " & 25 & $"$ & 37 & $"$ & 2 & $"$ & 47 & $"$ & 3 \\
\hline " & 18 & $"$ & 8 & & $"$ & 28 & $"$ & 75 & $"$ & 38 & $"$ & 15 & " & 48 & $"$ & 5 \\
\hline$"$ & 19 & $"$ & 13 & & $"$ & 29 & $"$ & 28 & $"$ & 39 & $"$ & 3 & $"$ & 49 & " & 0 \\
\hline$"$ & 20 & $"$ & 57 & & $"$ & 30 & $"$ & 132 & $"$ & 40 & $"$ & 37 & $"$ & 50 & $"$ & 19 \\
\hline$"$ & 21 & $"$ & 40 & & $"$ & 31 & $"$ & 7 & $"$ & 41 & " & 2 & $"$ & 51 & $"$ & 0 \\
\hline$"$ & 22 & " & 35 & & $"$ & 32 & $"$ & 25 & $"$ & 42 & $"$ & 7 & $"$ & 52 & $"$ & 5 \\
\hline$"$ & 23 & $"$ & 81 & & $"$ & 33 & $"$ & 12 & $"$ & 43 & $"$ & 5 & " & 53 & $"$ & 2 \\
\hline$"$ & 24 & " & 23 & & " & 34 & $"$ & 5 & $"$ & 44 & $"$ & 2 & $"$ & 54 & $"$ & 1 \\
\hline$"$ & 25 & " & 195 & & " & 35 & $"$ & 60 & $"$ & 45 & $"$ & 16 & $"$ & 55 & " & 1 \\
\hline
\end{tabular}

A fim de obtermos informações mais precisas sôbre a idade das mulheres, exigiamos, sempre que possivel, um documento comprovante. Quando isso não era viável e desconfiavamos de que a informação estava longe da verdade, va- 
liamo-nos da experiência da dona da casa, e as diferenças porventura existentes devem ser mínimas.

$$
\text { II - CÔR }
$$

Encontramos 550 mulheres brancas, 300 pardas e 150 pretas. Deve-se notar que as mulheres pardas e pretas residem, principalmente, nas ruas Itabóca, Ribeiro de Lima e Carmo Cintra. A rua Aimorés é quasi tôda habitada por mulheres de cor branca.

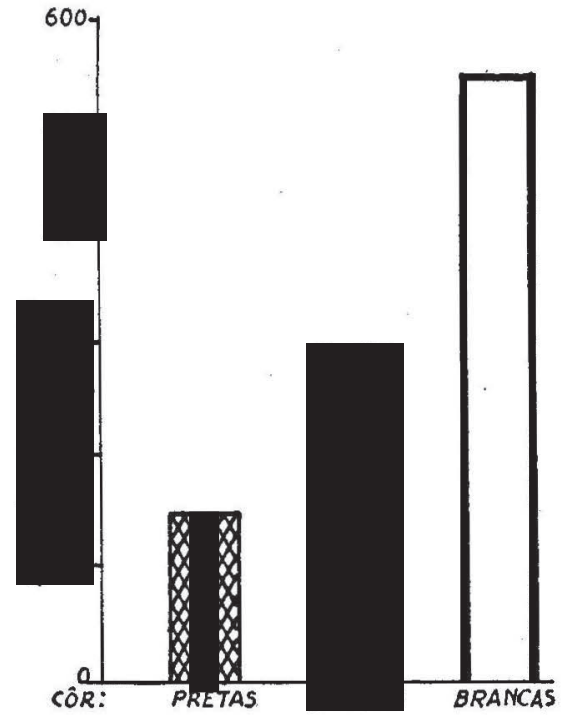

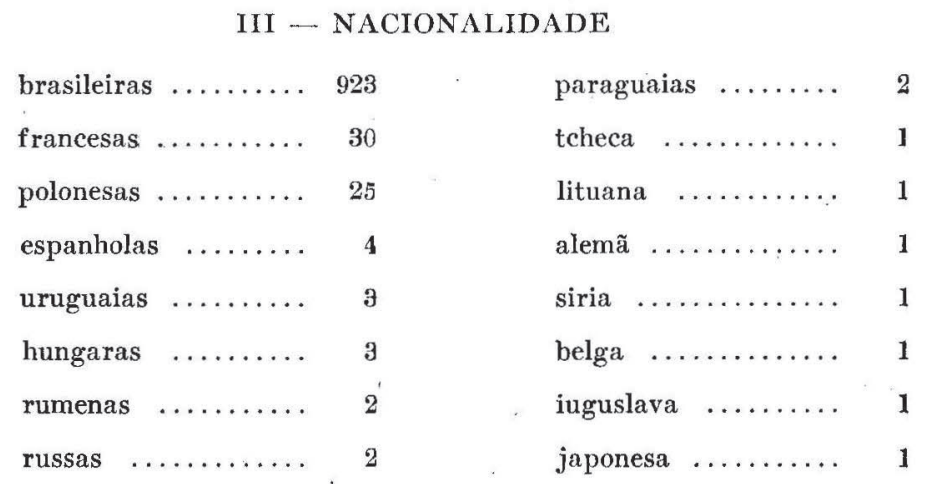




\section{IV - INDICE DE ALFABETIZAÇĀO}

Fizemos um inquérito entre 830 mulheres e encontramos 435 analfabetas. Essa porcentagem de $52,4 \%$ está, mais ou menos, de acôrdo com o índice de analfahetismo da mulher brasileira que é, segundo o Censo de 1940, de $60 \%$.

Prevalência da sifilis - Os sanitaristas estão de acôrdo em que as taxas de sífilis entre as prostitutas sejam as mais altas possíveis. Não há, porém, muitos trabalhos recentes sôbre o assunto. Em 1917 foram feitas algumas observaçōes entre prostitutas de diversos estados norte-americanos, e o resultado da incidência da sifilis entre elas variava de 60 a $70 \%$.

Nós colhemos amostras de sangue de 1.000 mulheres da zona do meretrício de São Paulo, para fins de diagnóstico da sífilis. Foram feitas as reações de Wassermann e Kahn em tôdas essas amostras, no Laboratório de Bacteriologia da Faculdade de Higiene e Saúde Pública, sendo colhido novo material e repetidas as reações nos casos duvidosos.

Foram encontradas 836 reaçôes positivas, ou seja $83,6 \%$ do total.

Deve-se notar que dessas 836 mulheres com reações positivas, $362(43,3 \%)$ exerciam a prostituição há menos de 4 anos, sendo provavelmente portadoras de sífilis recente; contagiantes, portanto.

Devemos esclarecer que procuramos tirar dessas 1.000 mulheres o maior número de dados referentes à história anterior de sífilis, principalmente sôbre resultados de exame de sangue e tratamentos específicos realizados. Dessa maneira pudemos classificar como sendo positivos muitos dos resultados duvidosos, 6 mesmo alguns negativos.

\section{REFERENCIAS}

D. F. Smiley \& A. G. Gould - Personal and community Hygiene, 1944.

M. O. Morais - Estado atual da prostituição no Rio de Janeiro - Folha Médica - Julho de 1942.

José Lentino - O problema da Sífilis em São Paulo, 1930.

J. J. Frappa - Enquete sur la Prostitution, Paris, 1937.

J. H. Stokes - Informe sobre la Prostitución en el Control de las enfermedades venereas - Inform. sobre enf. ven., abril, 1943.

A. Flexner - La Prostitution en Europe. 